\title{
Prospective Effects of Emotion-Regulation Skills on Emotional Adjustment
}

\author{
Matthias Berking \\ University of Washington \\ Peggilee Wupperman \\ Yale University
}

\author{
Ulrich Orth \\ University of California, Davis
}

Laurenz L. Meier and Franz Caspar
University of Bern

\begin{abstract}
Deficits in emotion-regulation skills have widely been shown to be associated with poor emotional adjustment. However, it is still unclear whether these deficits are a cause or a consequence of poor adjustment. The purpose of the present research was to clarify the reciprocal effects between these 2 concepts. In 2 studies ( $N$ s $=446$ and 635), self-reports of emotion regulation and emotional adjustment were assessed twice with a 2-week interval. Cross-lagged regression analyses demonstrated that selfreports of emotion regulation predicted subsequent adjustment, over and above the effects of previous adjustment, whereas emotional adjustment did not predict subsequent emotion regulation. Thus, a focus on emotion-regulation skills may be important in the prevention and treatment of affect-related mental health problems.
\end{abstract}

Keywords: affect, emotional adjustment, emotion regulation, risk factors, skills

The ability to deal effectively with negative emotions is widely thought to be integral to mental health (Gross \& Muñoz, 1995; Kring \& Werner, 2004). Deficits in general emotion-regulation abilities, such as perceiving, understanding, modifying, and accepting negative emotions, are thought to increase negative affect, decrease positive affect, and reduce emotion-related self-efficacy, thus prompting dysfunctional behavior as a means of avoiding negative emotions (e.g., Berking, 2007; Grawe, 2006). ${ }^{1}$ This line of reasoning is supported by numerous cross-sectional studies showing that general emotion-regulation deficits are associated with more negative and less positive affect (e.g., Berking \& Znoj, 2008) and with various forms of psychopathology, such as depression (Silk, Steinberg, \& Morris, 2003; Williams, Fernández-Berrocal, Extremera, Ramos-Díaz, \& Joiner, 2004), anxiety (Feldner, Zvolensky, \& Leen Feldner, 2004; Marchesi, Fontò, Balista, Cimmino, \& Maggini, 2005; Mennin, Heimberg, Turk, \& Fresco, 2005), substance abuse (Fox, Axelrod, Paliwal, Sleeper, \& Sinha, 2007; Isenhart, 1991), eating disorders (Bydlowski et al., 2005; Sim \& Zeman, 2004), attention-deficit hyperactivity disorder (Walcott \& Landau, 2004), and borderline personality disorder (Gratz, Rosenthal, Tull, Lejuez, \& Gunderson, 2006).

Matthias Berking, Department of Psychology, University of Washington; Ulrich Orth, Department of Psychology, University of California, Davis; Peggilee Wupperman, Department of Psychiatry, Yale University; Laurenz L. Meier and Franz Caspar, Department of Psychology, University of Bern, Bern, Switzerland.

This research was supported by Swiss National Science Foundation Grant PA001-113040 to Matthias Berking and by Swiss National Science Foundation Grant PA001-113065 to Ulrich Orth.

Correspondence concerning this article should be addressed to Matthias Berking, who is now at the Department of Psychology, University of Bern, Gesellschaftsstrasse 49, CH-3013 Bern, Switzerland. E-mail: Matthias .Berking@psy.unibe.ch
On the basis of these findings, it has been suggested that the effectiveness of psychological interventions could be enhanced by targeting general emotion-regulation deficits that are involved in the development and maintenance of mental health problems (Berking, 2007; Hollon et al., 2002; Moses \& Barlow, 2006). Interventions that focus explicitly on enhancing general emotionregulation skills have indeed been shown to be effective for a wide range of mental disorders. For example, there is at least preliminary evidence that dialectical behavior therapy (Linehan, 1993) is not only effective in the treatment of borderline personality disorder (Lynch, Trost, Salsman, \& Linehan, 2007) but also in the treatment of substance abuse (Linehan et al., 2002), eating disorders (Safer, Telch, \& Agras, 2001; Telch, Agras, \& Linehan, 2001), and depression in older adults (Lynch, Morse, Mendelson, \& Robins, 2003). Additional examples of promising treatments that focus on general emotion-regulation skills include treatments for binge eating disorder (Clyne \& Blampied, 2004), posttraumatic stress disorder related to childhood abuse (Cloitre, Koenen, Cohen, \& Han, 2002), and generalized anxiety disorder (Mennin, Heimberg, Turk, \& Fresco, 2002), as well as an acceptance-based emotion-regulation training for borderline personality disorder (Gratz \& Gunderson, 2006).

The following general emotion-regulation skills have been specified as important for mental health: the ability to (a) consciously process emotions/be aware of emotions (e.g., Lischetzke \& Eid, 2003), (b) identify and label emotions (e.g., Bagby, Parker, \& Taylor, 1994; Feldman-Barrett, Gross, Christensen, \& Benvenuto,

\footnotetext{
${ }^{1}$ To avoid awkward formulations, we subsume concepts such as understanding, accepting, and tolerating emotions under the term emotion regulation if not otherwise indicated. Such a broad definition of the term is justified because these skills have significant impact on the nature and intensity of an emotion and can therefore be seen as part of the regulation process (cf. Gross, 1998; Larsen, 2000).
} 
2001), (c) interpret emotion-related body sensations correctly (e.g., Damasio, 1994; Marchesi et al., 2005), (d) understand the prompts of emotions (e.g., Southam-Gerow \& Kendall, 2002), (e) accept emotions (e.g., Greenberg, 2002; Hayes, Strohsahl, \& Wilson, 1999; Leahy, 2002), (f) tolerate emotions (e.g., Kabat-Zinn, 2003; Kobasa, Maddi, \& Kahn, 1982), (g) confront emotionally distressing situations to attain important goals (e.g., Hayes, Wilson, Gifford, Follette, \& Strosahl, 1996; Margraf \& Berking, 2005), and (h) actively modify negative emotions to feel better (e.g., Catanzaro \& Greenwood, 1994; Salovey, Mayer, Goldman, Turvey, \& Palfai, 1995).

However, before concluding that emotion-regulation abilities such as these help maintain and improve mental health, one must provide evidence that the effects of the above-mentioned treatments are mediated by improved emotion-regulation skills and that cross-sectional studies do not simply reflect interference of impaired emotional adjustment with successful emotion regulation (e.g., dysphoric affect reducing the ability to regulate one's emotions successfully). Unfortunately, only limited research has addressed these questions.

To identify causal effects, one must clarify the temporal relationship between successful emotion regulation and emotional adjustment. At this point, there is some evidence from experimental studies that deficient emotion-regulation abilities precede affect-related aspects of mental health. For example, a study of panic patients found that the instruction to accept one's emotions was associated with less subsequent anxiety in response to a carbon dioxide challenge paradigm than was the instruction to suppress one's emotions (Levitt, Brown, Orsillo, \& Barlow, 2003). This effect was also found for participants with a high tendency to avoid aversive inner experiences (Feldner, Zvolensky, Eifert, \& Spira, 2003). Moreover, experimentally induced rumination-a cognitive process associated with avoidance of aversive experiences/emotions (Cribb, Moulds, \& Carter, 2006)— has been shown to intensify depressed mood (Morrow \& Nolen-Hoeksema, 1990), sadness (Conway, Csank, Holm, \& Blake, 2000), and anger (Rusting \& Nolen-Hoeksema, 1998). Therefore, there is evidence that the ability to accept one's emotions (vs. avoid them) precedes emotional adjustment. However, many other possibly important emotion-regulation skills have not yet been investigated in experimental studies, and experimental studies cannot clarify whether these short-term effects will have stable effects in a naturalistic environment.

Further support for the hypothesis that successful emotionregulation precedes emotional adjustment comes from coping research: Several studies suggest that avoidance-focused coping predicts mental health problems at a later point in time (e.g., Herman-Stabl, Stemmler, \& Petersen, 1995; Seiffge-Krenke, 2000); and a number of "cognitive emotion-regulation strategies" are associated with subsequent levels of depression and anxiety (Garnefski \& Kraaij, 2007; Kraaij, Pruymboom, \& Garnefski, 2002). However, these and other coping studies assess ways in which participants deal with stressful situations. Thus, it is not clear whether the coping behavior refers to the emotions cued in these situations or to other aspects of the situation. Similar problems occur with studies assessing rumination: Ruminating about symptoms of depression predicted level of anxiety and depression at a later point in time (Nolen-Hoeksema, 2000; Nolen-Hoeksema \& Harrell, 2002), but it is not clear whether participants ruminated about the negative emotions that are associated with depression or about other depression-related symptoms and/or impairments. Finally, Cohen, Gunthert, Butler, O'Neill, and Tolpin (2005) showed in an experience sampling study that daily affective reactivity toward stressful events was associated with (a) subsequent levels of depression in a college student sample and (b) less success in subsequent cognitive behavioral treatment for depression in a clinical sample. These results suggest that the inability to stabilize one's mood in aversive circumstances is an important factor in the development and maintenance of depression. However, it remains unclear whether the ability to stabilize mood is due to the successful application of emotion-regulation skills, which can be targeted and improved in treatment (e.g., Berking, 2007), or, instead, due to more stable personality traits (e.g., Kokkonen \& Pulkkinen, 2001).

In sum, many cross-sectional and intervention studies suggest that general emotion-regulation skills are negatively associated with psychopathology, and there is evidence that some specific emotion-regulation skills have an immediate effect on emotional adjustment. However, there is only limited evidence indicating that deficits in the application of relevant emotion-regulation skills precede deficits in emotional adjustment in naturalistic settings. Thus, we conducted two longitudinal studies to examine the reciprocal effects between emotion regulation and emotional adjustment over time. The first focused on a community sample $(N=$ $446)$, and the second was a web-based study $(N=635)$ with participants recruited from readers of an article about causes and treatments of depression in a popular German health magazine. In each study, we assessed self-reports of successful emotion regulation and indicators of emotional adjustment at two time points, with a 2-week interval.

\section{Study 1}

\section{Method}

Participants. Participants were solicited from individuals in the pedestrian area of downtown Bern, Switzerland, and were asked whether they would participate in a study, described to them as "a survey about how people manage their feelings." Members of the research team estimated that about one in four persons approached agreed to participate. Usable data were collected from 446 individuals. Participants were between 18 and 76 years of age $(M=32.99, S D=12.59) ; 70 \%$ were women. Regarding highest achieved education level, $4 \%$ had 10 years of education or less, $38 \%$ had completed high school, $35 \%$ had completed a professional education, and $22 \%$ had obtained a university degree. All participants were Caucasian. Because the study was conducted in German, only fluent German speakers were invited to participate.

Measures. For the assessment of successful emotion regulation, we used the total score of the Fragebogen zur Selbsteinschätzung emotionaler Kompetenzen (German for Emotion-Regulation Skills Questionnaire [ERSQ]; Berking \& Znoj, 2008). ${ }^{2}$ The ERSQ is a self-report instrument that assesses successful application of the eight emotion-regulation skills described in the introduction on a 5-point Likert-type scale ( $0=$ not at all, $4=$ almost always $)$. Each of the skills is assessed with three items. The items of the

\footnotetext{
${ }^{2}$ An English version of the questionnaire, which is currently being validated in several studies, will soon be available through Matthias Berking.
} 
ERSQ are preceded by the stem, "Last week ...." Items include "I paid attention to my feelings"; "my physical sensations were a good indication of how I was feeling"; "I was clear about what emotions I was experiencing"; "I was aware of why I felt the way I felt"; "I accepted my emotions"; "I felt I could cope with even intense negative feelings"; "I did what I had planned, even if it made me feel uncomfortable or anxious"; and "I was able to influence my negative feelings." To assess successful emotion regulation, one can compute a total score by averaging all of the items. Cronbach's $\alpha$ and 2-week retest reliability for the total score in a community-based sample were .90 and .75 , respectively (Berking \& Znoj, 2008). In support of the validity of the scale, the total score has been shown to be associated positively with measures of well-being and mental health and negatively with measures of ill-being and psychopathology in both community-based (Berking \& Znoj, 2008) and clinical (Berking et al., in press) samples. Sensitivity to change has been demonstrated in several samples of patients undergoing psychotherapeutic treatment (Berking \& Znoj, 2008; Berking et al., in press), as well as in at-risk samples (e.g., police officers) participating in an intensive emotion-regulation training (e.g., Berking, Meier, \& Wupperman, 2008). As shown in Table 1, Cronbach's $\alpha$ for the total scores in Study 1 was .89 at Time 1 and .94 at Time 2 .

As indicators of emotional adjustment, both negative and positive affect were assessed with the German version of the Positive and Negative Affect Schedule (PANAS; original version, Watson, Clark, \& Tellegen, 1988; German version, Krohne, Egloff, Kohlmann, \& Tausch, 1996). This measure consists of 20 items describing positive and negative affective states; participants use a 5-point Likert-type scale $(0=$ not at all, $4=$ almost always $)$ to rate the frequency of these states in a certain time frame. For the German version, the internal consistency of both scales in a community-based sample was .84 or higher. Consistent with theoretical expectations, significant correlations were reported with related constructs, such as anxiety, depression, and neuroticism (Krohne et al., 1996). For this study, we asked participants to assess the previous week, to cover the same time period as the ERSQ. As can be seen in Table 1, internal consistency of the PANAS ranged from .82 to .90 .

Procedures. Participants were recruited by research assistants and students of the University of Bern (Switzerland). Recruiters were instructed to address people at random. No incentive was offered for participation. Each consenting participant received an envelope with two sets of questionnaires and a stamped envelope in which to return the questionnaires to the research team. Participants were instructed to complete one set of questionnaires at the beginning of a 2 -week interval and the other at the end. Returned questionnaires in which given dates of assessments were fewer than 12 days or more than 16 days apart were not included in the study. Code names were used to ensure confidentiality. About $89 \%$ of potential participants returned both sets of questionnaires. Of all returned questionnaires, $11(2 \%)$ were not usable because of incomplete data, and $27(6 \%)$ were excluded because they were not completed in the correct time span.

\section{Results}

To investigate the direction of prospective effects, we used cross-lagged regression analyses based on structural equation modeling (e.g., Finkel, 1995). This method allows the investigation of time-lagged reciprocal effects of two variables while controlling for autoregression effects (Cole \& Maxwell, 2003). Moreover, this method allowed us to control for random measurement error by analyzing the constructs as latent variables and control for nonrandom measurement error by accounting for variance related to specific indicators and occasions.

For the structural equation models, we used item parcels as indicators because they produce more reliable latent variables than do individual items (Little, Cunningham, Shahar, \& Widaman, 2002). For the emotion regulation and emotional adjustment variables, we randomly aggregated the items into three parcels. Fixation of factor loadings was used as the scaling method; for each factor, the unstandardized value of the first loading was set to 1 . Table 2 shows that all loadings of the measured variables on the latent variables were statistically significant. To test for measurement invariance, we compared the fit of two measurement models. In the first measurement model, we freely estimated the factor loadings for both assessments; all factors were correlated, and we correlated the uniquenesses of individual indicators over time. The second measurement model was identical to the first except that we constrained the factor loadings of each indicator to be equal across time. If the fit of the constrained model is not worse than that of the unconstrained model, the constraints are empirically justified and ensure that the latent constructs are measured similarly at both points of assessment.

Table 1

Bivariate Correlations, Reliabilities, Means, and Standard Deviations of Measures (Study 1)

\begin{tabular}{|c|c|c|c|c|c|c|c|c|}
\hline Measure & $M$ & $S D$ & 1 & 2 & 3 & 4 & 5 & 6 \\
\hline \multicolumn{9}{|c|}{ Time 1} \\
\hline 1. Emotion regulation & 2.77 & 0.50 & .89 & -.34 & .46 & .77 & -.29 & .43 \\
\hline 2. Negative affect & 0.89 & 0.60 & & .82 & -.41 & -.27 & .67 & -.26 \\
\hline 3. Positive affect & 2.45 & 0.70 & & & .88 & .37 & -.27 & .62 \\
\hline \multicolumn{9}{|c|}{ Time 2} \\
\hline 4. Emotion regulation & 2.05 & 0.69 & & & & .94 & -.39 & .57 \\
\hline 5. Negative affect & 2.09 & 0.70 & & & & & .85 & -.46 \\
\hline 6. Positive affect & 1.55 & 0.71 & & & & & & .90 \\
\hline
\end{tabular}

Note. $\quad N=446$. Coefficient alphas are represented in boldface along the diagonal. All correlations are significant at $p<.001$. 
Table 2

Factor Loadings for the Measurement Model (Study 1)

\begin{tabular}{|c|c|c|c|c|c|}
\hline Model and indicator & $\ell_{\mathrm{u}}$ & $S E$ & $Z$ & $\ell_{\mathrm{st1}}$ & $\ell_{\mathrm{st2}}$ \\
\hline \multicolumn{6}{|c|}{ ER-NA } \\
\hline $\begin{array}{l}\text { Emotion regulation } \\
\text { latent construct }\end{array}$ & & & & & \\
\hline Parcel 1 & 1.00 & & & .83 & .85 \\
\hline Parcel 2 & 1.07 & .04 & 30.11 & .90 & .93 \\
\hline Parcel 3 & 1.08 & .04 & 29.26 & .87 & .90 \\
\hline \multicolumn{6}{|l|}{$\begin{array}{l}\text { Emotional adjustment } \\
\text { latent construct }\end{array}$} \\
\hline Parcel 1 & 1.00 & & & .81 & .85 \\
\hline Parcel 2 & 0.84 & .05 & 18.38 & .75 & .79 \\
\hline Parcel 3 & 0.77 & .05 & 17.16 & .67 & .70 \\
\hline \multicolumn{6}{|c|}{ ER-PA } \\
\hline \multicolumn{6}{|l|}{$\begin{array}{l}\text { Emotion regulation } \\
\text { latent construct }\end{array}$} \\
\hline Parcel 1 & 1.00 & & & .84 & .85 \\
\hline Parcel 2 & 1.06 & .04 & 30.64 & .90 & .93 \\
\hline Parcel 3 & 1.07 & .04 & 29.54 & .87 & .90 \\
\hline \multicolumn{6}{|l|}{$\begin{array}{l}\text { Emotional adjustment } \\
\text { latent construct }\end{array}$} \\
\hline Parcel 1 & 1.00 & & & .84 & .86 \\
\hline Parcel 2 & 1.07 & .04 & 26.59 & .81 & .84 \\
\hline Parcel 3 & 0.98 & .04 & 27.63 & .85 & .87 \\
\hline
\end{tabular}

Note. $\quad \mathrm{ER}=$ emotion regulation; $\mathrm{NA}=$ negative affect; $\mathrm{PA}=$ positive affect; $\ell_{\mathrm{u}}=$ unstandardized factor loadings; $\ell_{\mathrm{s}}=$ standardized factor loadings. All Zs are significant at $p<.001$.

For the computations, we used Amos 5 (Arbuckle, 2003) and SPSS 14.0 (SPSS, 2005). To deal with missing values, we employed the full information maximum likelihood procedure included in Amos. This procedure has been shown to provide less biased and more reliable results than conventional missing-data methods, such as listwise or pairwise deletion (Schafer \& Graham, 2002). In the current study, the rate of missing data was less than $3 \%$. Model fit was assessed by three fit indices recommended as most useful (Hu \& Bentler, 1998, 1999): the Tucker-Lewis Index (TLI), the comparative fit index (CFI), and the root-mean-square error of approximation (RMSEA). Hu and Bentler (1999) suggested that good fit is indicated by values greater than or equal to .95 for TLI and CFI and less than or equal to .06 for RMSEA. In addition, we report chi-square values and the $90 \%$ confidence interval for RMSEA.

As shown in Table 3, model fit was good for all unconstrained and constrained measurement models. Because chi-square differences between the unconstrained and the constrained models were not significant, we favored the more parsimonious model and retained the longitudinal constraints on factor loadings in the subsequent analyses. Next, we tested the fit of the cross-lagged models. In cross-lagged models, a latent variable at Time 2 is predicted by the same variable at Time 1 and the other latent variable at Time 1 (see Figure 1). The cross-lagged paths indicate the effect of one variable on the other, controlling for the stability of the variables over time. As can be seen in Table 3 , the structural model has the same fit as the constrained measurement model, because the models are fully equivalent and have the same modelimplied covariance matrix.

Figure 1 presents the structural part of the model. Successful emotion regulation is significantly associated with less negative affect and more positive affect. The cross-lagged effects from successful emotion regulation on negative affect and positive affect were significant. In contrast, the cross-lagged effects of negative and positive affect on successful emotion regulation were virtually zero and nonsignificant.

The results of Study 1 suggest that emotion regulation has a unidirectional effect on subsequent positive and negative affect, but there is a need to cross-validate the findings. Therefore, we conducted a second longitudinal study. In Study 2, we tested the effects of emotion regulation on a wider range of indicators of emotional adjustment, including depression and anxiety. Moreover, Study 2 assessed individuals who were at risk for mental disorders, whereas Study 1 used a purely nonclinical sample.

Study 2

\section{Method}

Participants. Participants for the web-based Study 2 were recruited by an article about possible causes and treatments of depression, which appeared in a depression-focused issue of a popular German health magazine. We reasoned that participants who would buy and read a magazine focusing on depression and spend time taking a web-based assessment would qualify at least

Table 3

Fit Indices (Study 1)

\begin{tabular}{lccrrrr}
\hline \multicolumn{1}{c}{ Measure } & $\chi^{2}$ & $d f$ & CFI & TLI & RMSEA & 90\% CI RMSEA \\
\hline Unconstrained measurement models & & & & & & \\
$\quad$ Negative affect & 55.77 & 42 & 1.00 & .99 & .025 & $.000-.042$ \\
$\quad$ Positive affect & $100.27^{* * * *}$ & 42 & .99 & .98 & .056 & $.042-.070$ \\
Constrained measurement models & & & & & & \\
$\quad$ Negative affect & 58.97 & 46 & 1.00 & .99 & .025 & $.000-.042$ \\
$\quad$ Positive affect & $106.73^{* * * *}$ & 46 & .99 & .98 & .054 & $.041-.068$ \\
Cross-lagged models & & & & & & \\
$\quad$ Negative affect & 58.97 & 46 & 1.00 & .99 & .025 & $.000-.042$ \\
$\quad$ Positive affect & $106.73^{* * *}$ & 46 & .99 & .98 & .054 & $.041-.068$ \\
\hline
\end{tabular}

Note. $\quad$ CFI $=$ comparative fit index; TLI $=$ Tucker-Lewis Index; RMSEA $=$ root-mean-square error of approximation; $\mathrm{CI}=$ confidence interval.

${ }^{* * * *} p<.001$. 

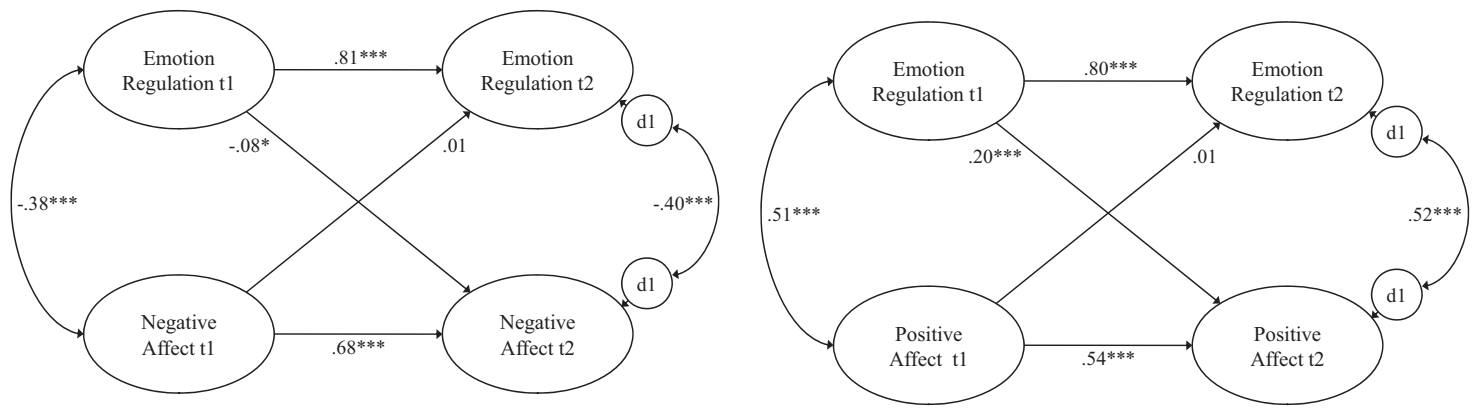

Figure 1. Structural model for reciprocal time-lagged effects between emotion regulation and aspects of emotional adjustment (Study 1). $\mathrm{d}=$ disturbances. ${ }^{*} p<.05 .{ }^{* * * *} p<.001$.

as an at-risk population for mental health problems. To ensure the validity of the analyses, we included participants only if they provided at least some information at both assessments. Of the 850 individuals who registered for the study, 635 participated in both assessments. The mean age of the final sample was 34.16 years $(S D=10.76$, range $=15-72) ; 75 \%$ were women. Regarding highest achieved educational level, $1 \%$ had no educational degree, $25 \%$ had graduated after at least 9 years of school, and $74 \%$ had a high school degree. Participants were from Germany (87\%), Switzerland (11\%), Austria (1\%), and other countries (1\%). As shown in Table 4, the sample in Study 2 reported more negative affect, less positive affect, and less successful emotion regulation than the sample in Study 1, $t$ s $(1033,1078$, and 1079, respectively) $=$ $30.27,20.63$, and 19.79, respectively; all $p$ s $<.001$; Cohen's $d=$ $1.85,1.28$, and 1.20 , respectively. This supports our assumption that the sample in Study 2 was at higher risk for mental disorders than was the sample in Study 1. Additional analyses indicated that the final sample did not differ significantly from the sample that originally registered for the study with regard to age, sex, education, country of origin, and measures of emotion regulation and adjustment, as assessed at Time 1 .

Measures. To measure the successful regulation of negative emotions, negative affect, and positive affect, we used the ERSQ and the PANAS, as described in Study 1. To measure anxiety, we used an abbreviated version of the state scale of the State-Trait
Anxiety Inventory (STAI; original version, Spielberger, 1983; German version, Laux, Glanzmann, Schaffner, \& Spielberger, 1980). Cronbach's alpha of the German version of the STAI in a community-based sample was .90 and above; support for the validity of this scale is provided by significant correlations with related constructs in a community sample (Laux et al., 1980).

To assess symptoms of depression, we used an abbreviated version of the Center of Epidemiological Studies Depression Scale (CES-D; original version: Radloff, 1977, 1991; German version: Hautzinger \& Bailer, 1993). The German version of the CES-D has demonstrated a Cronbach's alpha of .89 in a community-based sample. The German CES-D has also displayed correlations of .72 and above with other measures of depression (e.g., Beck Depression Inventory; Beck, Ward, Mendleson, Mock, \& Erbaugh, 1961) in a clinical sample (Hautzinger \& Bailer, 1993).

To minimize the time needed to complete the web-based assessment, we used only those five items of the STAI and the CES-D that have shown the highest item-total correlations in the German versions $\left(r_{i t}=.60-.66\right.$ for the STAI, and $r_{i t}=.61-.76$ for the CES-D). In both questionnaires, we asked participants to report symptoms within the past week, similar to the instructions used for all other measures in both studies. In Study 2, internal consistencies were .77 and above for all scales (see Table 4).

Procedures. Readers of a depression-focused issue of a German health magazine were invited to participate in a web-based

Table 4

Bivariate Correlations, Reliabilities, Means, and Standard Deviations of Measures (Study 2)

\begin{tabular}{|c|c|c|c|c|c|c|c|c|c|c|c|c|}
\hline Measure & $M$ & $S D$ & 1 & 2 & 3 & 4 & 5 & 6 & 7 & 8 & 9 & 10 \\
\hline \multicolumn{13}{|c|}{ Time 1} \\
\hline 1. Emotion regulation & 2.05 & 0.69 & .94 & -.45 & .60 & -.45 & -.51 & .78 & -.41 & .51 & -.41 & -.41 \\
\hline 2. Negative affect & 2.09 & 0.70 & & .85 & -.52 & .71 & .63 & -.38 & .68 & -.36 & .53 & .48 \\
\hline 3. Positive affect & 1.55 & 0.71 & & & .90 & -.61 & -.70 & .50 & -.39 & .61 & -.45 & -.51 \\
\hline 4. Anxiety & 1.94 & 0.62 & & & & .77 & .67 & -.37 & .51 & -.38 & .59 & .46 \\
\hline 5. Depression & 1.87 & 0.70 & & & & & .83 & -.41 & .49 & -.48 & .48 & .63 \\
\hline \multicolumn{13}{|c|}{ Time 2} \\
\hline 6. Emotion regulation & 2.19 & 0.70 & & & & & & .94 & -.51 & .66 & -.54 & -.53 \\
\hline 7. Negative affect & 1.86 & 0.73 & & & & & & & .87 & -.59 & .74 & .71 \\
\hline 8. Positive affect & 1.76 & 0.76 & & & & & & & & .92 & -.65 & -.75 \\
\hline 9. Anxiety & 1.81 & 0.68 & & & & & & & & & .82 & .74 \\
\hline 10. Depression & 1.61 & 0.78 & & & & & & & & & & .87 \\
\hline
\end{tabular}

Note. $\quad N=635$. Coefficient alphas are represented in boldface along the diagonal. All correlations are significant at $p<.001$. 
study that would provide individual feedback on their (a) level of depression, (b) risk factors for the development of depression (i.e., negative mood, higher levels of anxiety), and (c) protective factors that impede the development of depression (i.e., positive mood, effective emotion-regulation skills). Readers were informed that individual computerized feedback would be provided after the final assessment. The feedback contained information on the individual's scores compared with a reference population, the development of the assessed variables over time, and educational information about the key constructs of the study (including information on diagnostic and treatment possibilities).

Potential participants accessed the study at a noncommercial, advertisement-free website that was located within the domain of the University of Bern. Connections to this web page and data stored on the server were protected from unauthorized access. Code names and passwords were used to secure confidentiality. Participants were asked to provide an e-mail address at which they could receive e-mails containing individual links for subsequent assessment. These links were sent 13 days after initial assessment.

\section{Results}

The procedure for the statistical analysis was identical to the one used in Study 1. The rate of missing data was less than 1\%. For the five-item versions of the STAI and the CES-D, we assigned two items to two parcels each; the third parcel consisted of only one item. Table 5 shows that all loadings of measured variables on latent variables were significant. As shown in Table 6, the fit of all measurement models was at least acceptable, regardless of whether or not factor loadings were constrained to be equal over time. Because chi-square differences between constrained and unconstrained models were nonsignificant, we retained the longitudinal constraints on factor loadings in the subsequent analyses. Table 6 also shows that model fit was acceptable for anxiety and good for all other indicators of emotional adjustment.

The cross-sectional effects between successful emotion regulation and different aspects of emotional adjustment are shown in Figure 2. Successful emotion regulation significantly correlated with all indicators of adjustment. Moreover, emotion regulation is significantly associated with subsequent negative affect, positive affect, and anxiety, but not with subsequent depression. In contrast, none of the indicators of emotional adjustment predicted subsequent success in emotion regulation.

\section{General Discussion}

The main goal of the present research was to investigate the reciprocal relationship between successful emotion regulation and indicators of emotional adjustment. Therefore, we conducted two longitudinal studies: one with a community sample of 446 participants and another with a sample of 635 participants, who arguably had a higher risk for the development of mental health problems.

With regard to the cross-sectional association, successful emotion regulation was moderately associated with negative affect and strongly associated with positive affect, anxiety, and depression. With regard to the prospective effects, successful emotion regulation significantly predicted increased positive affect and decreased negative affect and anxiety, even when we controlled for the effects of previous emotional adjustment. In contrast, indicators of
Table 5

Factor Loadings for the Measurement Model (Study 2)

\begin{tabular}{lccccc}
\hline Model and indicator & $\ell_{\mathrm{u}}$ & $S E$ & $Z$ & $\ell_{\mathrm{st1}}$ & $\ell_{\mathrm{st} 2}$ \\
\hline & \multicolumn{2}{c}{ ER-NA } & & & \\
Emotion regulation & & & & & \\
$\quad$ latent construct & & & & .89 & .91 \\
Parcel 1 & 1.00 & & & .96 & .98 \\
Parcel 2 & 1.08 & .02 & 56.96 & .92 & .93 \\
Parcel 3 & 1.02 & .02 & 49.33 & & \\
Emotional adjustment & & & & & \\
$\quad$ latent construct & & & & .82 & .83 \\
Parcel 1 & 1.00 & & & .77 & .77 \\
Parcel 2 & 0.94 & .04 & 24.27 & .75 & .77 \\
Parcel 3 & 1.00 & .04 & 23.58 & .77 \\
\hline
\end{tabular}

ER-PA

\begin{tabular}{|c|c|c|c|c|c|}
\hline \multicolumn{6}{|c|}{$\begin{array}{l}\text { Emotion regulation } \\
\text { latent construct }\end{array}$} \\
\hline Parcel 1 & 1.00 & & & .90 & .91 \\
\hline Parcel 2 & 1.07 & .02 & 57.39 & .96 & .97 \\
\hline Parcel 3 & 1.02 & .02 & 50.24 & .92 & .93 \\
\hline \multicolumn{6}{|c|}{$\begin{array}{c}\text { Emotional adjustment } \\
\text { latent construct }\end{array}$} \\
\hline Parcel 1 & 1.00 & & & .85 & \\
\hline Parcel 2 & 1.01 & .03 & 33.51 & .82 & \\
\hline Parcel 3 & 0.96 & .03 & 36.09 & .85 & .89 \\
\hline \multicolumn{6}{|c|}{ ER-AN } \\
\hline \multicolumn{6}{|c|}{$\begin{array}{l}\text { Emotion regulation } \\
\text { latent construct }\end{array}$} \\
\hline Parcel 1 & 1.00 & & & .89 & .9 \\
\hline Parcel 2 & 1.08 & .02 & 57.04 & .96 & \\
\hline Parcel 3 & 1.02 & .02 & 49.37 & .92 & .9 \\
\hline \multicolumn{6}{|c|}{$\begin{array}{c}\text { Emotional adjustment } \\
\text { latent construct }\end{array}$} \\
\hline Parcel 1 & 1.00 & & & .76 & .71 \\
\hline Parcel 2 & 0.89 & .05 & 16.39 & .72 & \\
\hline Parcel 3 & 1.01 & .07 & 14.64 & .56 & \\
\hline
\end{tabular}

ER-DE

Emotion regulation

latent construct

Parcel 1

Parcel 2

1.00

Parcel 3

1.08

1.02

.02

57.10

49.57

.89

.96

.91

Emotional adjustment

latent construct

Parcel 1

Parcel 2

1.00

Parcel 3

0.96

0.89

$.04 \quad 21.58$

17.19

\section{.75}

80

$.53 \quad .61$

Note. $\quad \mathrm{ER}=$ emotion regulation; $\mathrm{NA}=$ negative affect; $\mathrm{PA}=$ positive affect; $\mathrm{AN}=$ anxiety; $\mathrm{DE}=$ Depression; $\ell_{\mathrm{u}}=$ unstandardized factor loadings; $\ell_{\mathrm{s}}=$ standardized factor loadings. All Zs are significant at $p<$ .001 .

emotional adjustment had no prospective effects on successful emotion regulation. Finally, emotion regulation did not predict subsequent depression when previous emotional adjustment was controlled. Thus, for the most part, results support the hypothesis that successful emotion regulation facilitates emotional adjustment, as opposed to emotion regulation being merely a symptom of impaired emotional adjustment.

Although the cross-lagged effects are comparatively small (explaining at most $4 \%$ of the variance), effect sizes such as these are not uncommon in prospective studies. In addition, we simulta- 
Table 6

Fit Indices (Study 2)

\begin{tabular}{lcccccc}
\hline \multicolumn{1}{c}{ Measure } & \multicolumn{1}{c}{$\chi^{2}$} & $d f$ & CFI & TLI & RMSEA & 90\% CI RMSEA \\
\hline Unconstrained measurement models & & & & & & \\
$\quad$ Negative affect & $134.02^{* * *}$ & 42 & .99 & .98 & .057 & $.047-.068$ \\
$\quad$ Positive affect & $122.66^{* * * *}$ & 42 & .99 & .98 & .055 & $.044-.066$ \\
$\quad$ Anxiety & $267.02^{* * * *}$ & 42 & .97 & .94 & .092 & $.082-.103$ \\
$\quad$ Depression & $109.06^{* * * *}$ & 42 & .99 & .98 & .050 & $.039-.062$ \\
Constrained measurement models & & & & & & \\
$\quad$ Negative affect & $141.48^{* * * *}$ & 46 & .99 & .98 & .057 & $.047-.068$ \\
$\quad$ Positive affect & $128.28^{* * * *}$ & 46 & .99 & .98 & .053 & $.042-.064$ \\
$\quad$ Anxiety & $271.32^{* * * *}$ & 46 & .97 & .94 & .088 & $.078-.098$ \\
$\quad$ Depression & $112.27^{* * * *}$ & 46 & .99 & .98 & .048 & $.037-.059$ \\
Cross-lagged models & & & & & & \\
$\quad$ Negative affect & $141.48^{* * * *}$ & 46 & .99 & .98 & .057 & $.047-.068$ \\
$\quad$ Positive affect & $128.28^{* * * *}$ & 46 & .99 & .98 & .053 & $.042-.064$ \\
$\quad$ Anxiety & $271.32^{* * * *}$ & 46 & .97 & .94 & .088 & $.078-.098$ \\
$\quad$ Depression & $112.27^{* * * *}$ & 46 & .99 & .98 & .048 & $.037-.059$ \\
\hline
\end{tabular}

Note. $\quad$ CFI $=$ comparative fit index; TLI $=$ Tucker-Lewis Index; RMSEA $=$ root-mean-square error of approximation; $\mathrm{CI}=$ confidence interval.

**** $p<.001$.

neously controlled for concurrent relations between variables and the longitudinal stability of each variable over time. The finding that the cross-lagged effect on depression was nonsignificant has more than one possible explanation. First, emotion-regulation deficits simply may not predict depression; however, theory and findings from previous research suggest otherwise (e.g., Cohen et al., 2005). Another possible explanation is that difficulties in emotion regulation may take longer than 2 weeks to lead to manifest symptoms of depression. This second explanation is supported by findings indicating that repeated and ongoing failures of coping efforts are usually required before one's situation is appraised as uncontrollable and stable over time, a process considered to be an important antecedent for the development of depression (e.g., Teasdale \& Barnard, 1993).

Several limitations need to be addressed. First, the large number of participants, multiple assessments, and web-based data collection required the use of self-report instruments for all variables; Study 2 also used abbreviated versions of the STAI and the
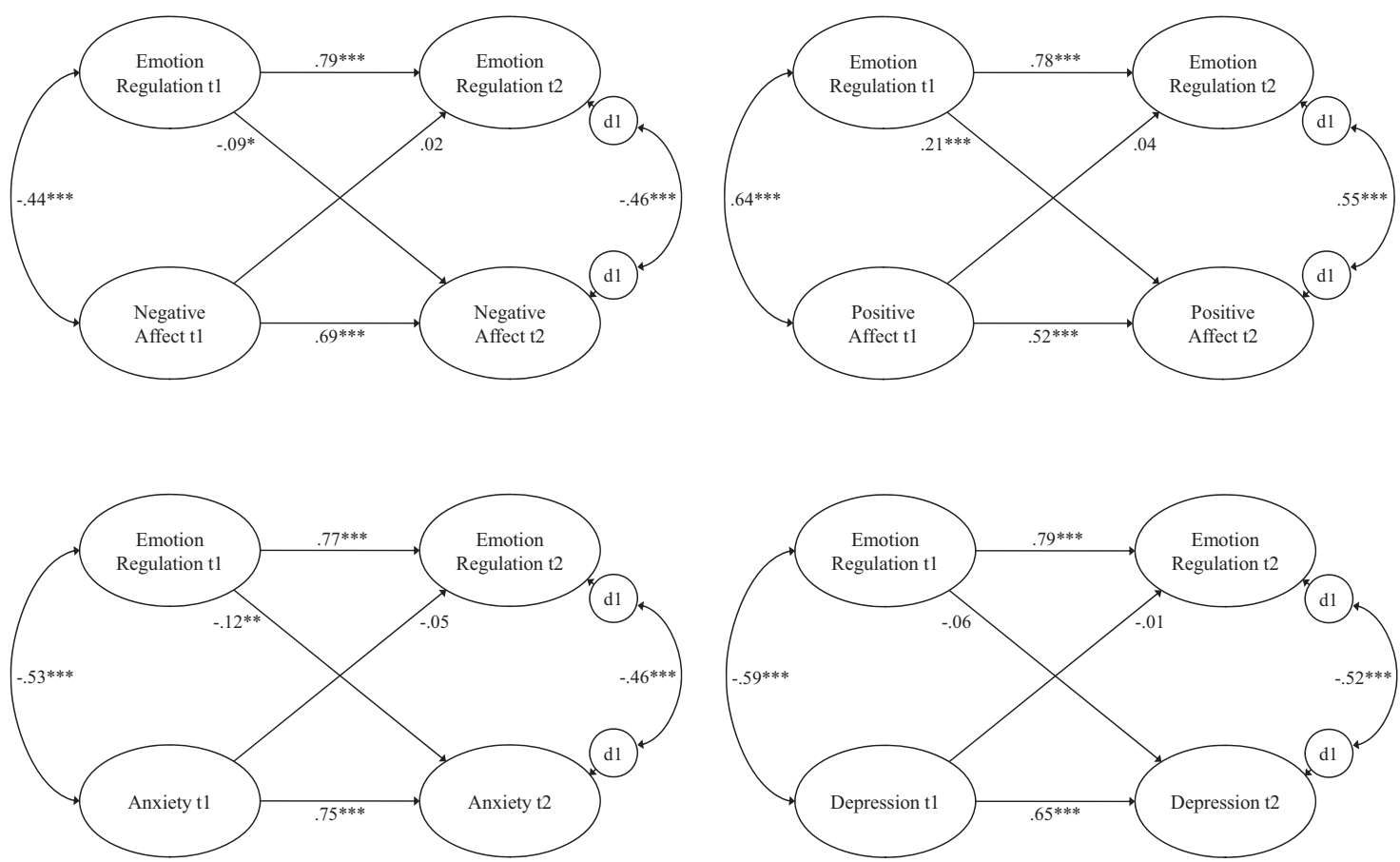

Figure 2. Structural model for reciprocal time-lagged effects between emotion regulation and aspects of emotional adjustment (Study 2). $\mathrm{d}=$ disturbances. ${ }^{*} p<.05 .{ }^{* * *} p<.01 .{ }^{* * * *} p<.001$. 
CES-D. It has been argued that the validity of self-reports of emotional competence is limited (e.g., Stankov, 1999). However, subjective appraisals of emotion regulation may often be at least as valid as alternative measures of emotion regulation (e.g., Brackett \& Mayer, 2003), such as observer ratings, standardized tests, or experiential measures. Nevertheless, it is important that future studies replicate the analyses using the original unabbreviated instruments, as well as multiple informants and/or additional assessment approaches. Second, participants in both samples were relatively young and had higher-than-average education, and results from a community-based and an at-risk sample may not necessarily generalize to clinical populations. Therefore, these findings need to be replicated with older and less educated participants who suffer from manifest mental disorders. Third, the validity and reliability of web-based studies have been questioned (e.g., Azar, 2000). However, recent research suggests that participants in web-based studies are as likely to take the study seriously and provide accurate information as are participants in traditional samples (Gosling, Vazire, Srivastava, \& John, 2004). Nevertheless, additional research is necessary before equivocally declaring that the results of Study 2 can be generalized to individuals unfamiliar with the internet. Finally, we addressed a 2-week time lag between two points of assessment in both studies. This comparatively short time span has the advantage of being more likely to address the direct effects of emotion regulation on emotional adjustment; in longer time spans, these effects might be mediated by multiple factors (e.g., quality of interpersonal relationships or work strain; Cote, 2005). The disadvantage of the 2-week lag is that it does not capture effects that require a longer time to occur. Thus, future studies should compare the effects of different time lags.

One strength of the present research is the convergence of findings across Studies 1 and 2, which helps alleviate methodological concerns and strengthens confidence in the results. For example, Study 1 used traditional data collection in a nonclinical community sample, whereas Study 2 used web-based data collection in a sample of individuals at higher risk for mental health problems. Additional marked strengths include the longitudinal design and the statistical models that allow precise measurements across assessments and controlled tests of reciprocal prospective effects.

With these strengths and limitations in mind, the present research suggests the following conclusions: Self-perception of successful emotion regulation is cross-sectionally associated with more positive affect, less negative affect, less anxiety, and less depression. For positive affect, negative affect, and anxiety, the association can be explained at least partly by prospective effects of emotion regulation on emotional adjustment. Although the analyses do not allow for definitive causal conclusions (as the observed effects could also be caused by confounding variables), these results provide support for the hypothesis that successful emotion regulation facilitates emotional adjustment, at least with regard to positive mood, negative mood, and anxiety. In contrast, none of the indicators of emotional adjustment predicted subsequent successful emotion regulation. Thus, the data do not support the assumption that emotion-regulation deficits are merely a consequence of affect-related mental health problems. This implies that fostering emotion-regulation skills may be an important target in the prevention and treatment of affect-related mental health problems. Consequently, future research should investigate the effectiveness of interventions that explicitly focus on building clients' emotion-regulation skills. Such interventions may be used as first-step measures and/or as adjunctive treatment components in the prevention and treatment of mental health problems.

\section{References}

Arbuckle, J. L. (2003). Amos 5.0 update to the Amos user's guide. Chicago: SPSS.

Azar, B. (2000). A web of research: They're fun, they're fast, and they save money, but do Web experiments yield quality results? Monitor on Psychology, 31, 42-47.

Bagby, R. M., Parker, J. D., \& Taylor, G. J. (1994). The twenty-item Toronto Alexithymia Scale II: Convergent, discriminant and concurrent validity. Journal of Psychosomatic Research, 38, 33-40.

Beck, A. T., Ward, C. H., Mendelson, M., Mock, J., \& Erbaugh, J. (1961). An inventory for measuring depression. Archives of General Psychiatry, 6, 561-571.

Berking, M. (2007). Training emotionaler Kompetenzen [Training of emotional competencies]. Heidelberg, Germany: Springer.

Berking, M., Meier, C., \& Wupperman, P. (2008). Enhancing emotionregulation skills in police officers: Results of a controlled study. Manuscript submitted for publication.

Berking, M., Wupperman, P., Reichardt, A., Pejic, T., Dippel, A., \& Znoj, $\mathrm{H}$. (in press). General emotion-regulation skills as a treatment target in psychotherapy. Behavior Research and Therapy.

Berking, M., \& Znoj, H. (2008). Entwicklung und Validierung eines Fragebogens zur standardisierten Selbsteinschätzung emotionaler Kompetenzen [Development and validation of a self-report measure for the assessment of emotion-regulation skills]. Zeitschrift für Psychiatrie, Psychologie und Psychotherapie, 56, 141-152.

Brackett, M. A., \& Mayer, J. D. (2003). Convergent, discriminant, and incremental validity of competing measures of emotional intelligence. Personality and Social Psychology Bulletin, 29, 1147-1158.

Bydlowski, S., Corcos, M., Jeammet, P., Paterniti, S., Berthoz, S., Laurier C., et al. (2005). Emotion-processing deficits in eating disorders. International Journal of Eating Disorders, 37, 321-329.

Catanzaro, S. J., \& Greenwood, G. (1994). Expectancies for negative mood regulation, coping, and dysphoria among college students. Journal of Counseling Psychology, 41, 34-44.

Cloitre, M., Koenen, K. C., Cohen, L. R., \& Han, H. (2002). Skills training in affective and interpersonal regulation followed by exposure: A phasebased treatment for PTSD related to childhood abuse. Journal of Consulting and Clinical Psychology, 70, 1067-1074.

Clyne, C., \& Blampied, N. M. (2004). Training in emotion regulation as a treatment for binge eating: A preliminary study. Behaviour Change, 21, 269-281.

Cohen, L. H., Gunthert, K. C., Butler, A. C., O’Neill, S. C., \& Tolpin, L. H. (2005). Daily affective reactivity as a prospective predictor of depressive symptoms. Journal of Personality, 73, 1687-1713.

Cole, D. A., \& Maxwell, S. E. (2003). Testing mediational models with longitudinal data: Questions and tips in the use of structural equation modeling. Journal of Abnormal Psychology, 112, 558-577.

Conway, M., Csank, P. A. R., Holm, S. L., \& Blake, C. K. (2000). On assessing individual differences in rumination on sadness. Journal of Personality Assessment, 75, 404-425.

Cote, S. (2005). A social interaction model of the effects of emotion regulation on work strain. Academy of Management Review, 30, 509530 .

Cribb, G., Moulds, M. L., \& Carter, S. (2006). Rumination and experiential avoidance in depression. Behaviour Change, 23, 165-176.

Damasio, A. R. (1994). Descartes' error: Emotion, reason, and the human brain. New York: Grosset/Putnam.

Feldman-Barrett, L., Gross, J. J., Christensen, T. C., \& Benvenuto, M. 
(2001). Knowing what you're feeling and knowing what to do about it: Mapping the relation between emotion differentiation and emotion regulation. Cognition and Emotion, 15, 713-724.

Feldner, M. T., Zvolensky, M. J., Eifert, G. H., \& Spira, A. P. (2003). Emotional avoidance: An experimental test of individual differences and response suppression using biological challenge. Behaviour Research and Therapy, 41, 403-411.

Feldner, M. T., Zvolensky, M. J., \& Leen Feldner, E. W. (2004). A critical review of the empirical literature on coping and panic disorder. Clinical Psychology Review, 24, 123-148.

Finkel, S. E. (1995). Causal analysis with panel data. Thousand Oaks, CA: Sage.

Fox, H. C., Axelrod, S. R., Paliwal, P., Sleeper, J., \& Sinha, R. (2007). Difficulties in emotion regulation and impulse control during cocaine abstinence. Drug and Alcohol Dependence, 89, 298-301.

Garnefski, N., \& Kraaij, V. (2007). The Cognitive Emotion Regulation Questionnaire: Psychometric features and prospective relationships with depression and anxiety in adults. European Journal of Psychological Assessment, 23, 141-149.

Gosling, S. D., Vazire, S., Srivastava, S., \& John, O. P. (2004). Should we trust web-based studies? A comparative analysis of six preconceptions about internet questionnaires. American Psychologist, 59, 93-104.

Gratz, K. L., \& Gunderson, J. G. (2006). Preliminary data on an acceptance-based emotion regulation group intervention for deliberate self-harm among women with borderline personality disorder. Behavior Therapy, 37, 25-35.

Gratz, K. L., Rosenthal, M. Z., Tull, M. T., Lejuez, C. W., \& Gunderson, J. G. (2006). An experimental investigation of emotion dysregulation in borderline personality disorder. Journal of Abnormal Psychology, 115, $850-855$.

Grawe, K. (2006). Neuropsychotherapy: How the neurosciences inform effective psychotherapy. London: Erlbaum.

Greenberg, L. (2002). Emotion-focused psychotherapy: Coaching clients to work through their feelings. Washington, DC: American Psychological Association.

Gross, J. J. (1998). The emerging field of emotion regulation: An integrative review. Review of General Psychology, 2, 271-299.

Gross, J. J., \& Muñoz, R. F. (1995). Emotion regulation and mental health. Clinical Psychology: Science and Practice, 2, 151-164.

Hautzinger, M., \& Bailer, M. (1993). Allgemeine Depressions Skala [General Depression Scale]. Göttingen, Germany: Beltz Test GmbH.

Hayes, S. C., Strohsahl, K. D., \& Wilson, K. G. (1999). Acceptance and commitment therapy: An experiential approach to behavioral change. New York: Guilford Press.

Hayes, S. C., Wilson, K. G., Gifford, E. V., Follette, V. M., \& Strosahl, K. (1996). Experiential avoidance and behavioral disorders: A functional dimensional approach to diagnosis and treatment. Journal of Consulting and Clinical Psychology, 64, 1152-1168.

Herman-Stabl, M. A., Stemmler, M., \& Petersen, A. C. (1995). Approach and avoidant coping: Implications for adolescent mental health. Journal of Youth and Adolescence, 24, 649-665.

Hollon, S. D., Muñoz, R. F., Barlow, D. H., Beardslee, W. R., Bell, C. C., \& Bernal, G. et al. (2002). Psychosocial intervention development for the prevention and treatment of depression: Promoting innovation and increasing access. Biological Psychiatry, 52, 610-630.

Hu, L., \& Bentler, P. M. (1998). Fit indices in covariance structure modeling: Sensitivity to underparameterized model misspecification. Psychological Methods, 3, 424-453.

Hu, L., \& Bentler, P. M. (1999). Cutoff criteria for fit indexes in covariance structure analysis: Conventional criteria versus new alternatives. Structural Equation Modeling, 6, 1-55.

Isenhart, C. E. (1991). Factor structure of the Inventory of Drinking Situations. Journal of Substance Abuse, 3, 59-71.

Kabat-Zinn, J. (2003). Mindfulness-based intervention in context: Past, present, and future. Clinical Psychology: Science and Practice, 10, $144-156$

Kobasa, S. C., Maddi, S. R., \& Kahn, S. (1982). Hardiness and health: A prospective study. Journal of Personality and Social Psychology, 42, $168-177$.

Kokkonen, M., \& Pulkkinen, L. (2001). Extraversion and neuroticism as antecedents of emotion regulation and dysregulation in adulthood. European Journal of Personality, 15, 407-424.

Kraaij, V., Pruymboom, E., \& Garnefski, N. (2002). Cognitive coping and depressive symptoms in the elderly: A longitudinal study. Aging and Mental Health, 6, 275-281.

Kring, A. M., \& Werner, K. H. (2004). Emotion regulation and psychopathology. In P. Philipot \& R. S. Feldman (Eds.), The regulation of emotion (pp. 359-385). New York: LEA.

Krohne, H. W., Egloff, B., Kohlmann, C. W., \& Tausch, A. (1996). Untersuchungen mit einer deutschen Version der Positive and Negative Affect Schedule (PANAS) [Studies with a German version of the Positive and Negative Affect Scale (PANAS)]. Diagnostica, 42, 139-156.

Larsen, R. J. (2000). Toward a science of mood regulation. Psychological Inquiry, 11, 129-141.

Laux, L., Glanzmann, P., Schaffner, P., \& Spielberger, C. (1980). Das State-Trait-Angstinventar. Theoretische Grundlagen und Handanweisung [The State-Trait-Anxiety-Inventory: Theoretical background and instructions]. Beltz, Germany: Weinheim.

Leahy, R. L. (2002). A model of emotional schemas. Cognitive and Behavioral Practice, 9, 177-191.

Levitt, J. T., Brown, T. A., Orsillo, S. M., \& Barlow, D. H. (2003). The effects of acceptance versus suppression of emotion on subjective and psychophysiological response to carbon dioxide challenge in patients with panic disorder. Behavior Therapy, 35, 747-766.

Linehan, M. M. (1993). Cognitive-behavioral treatment of borderline personality disorder. New York: Guilford Press.

Linehan, M. M., Dimeff, L. A., Reynolds, S. K., Comtois, K. A., Welch, S. S., Heagerty, P., \& Kivlahan, D. R. (2002). Dialectical behavior therapy versus comprehensive validation therapy plus 12-step for the treatment of opioid dependent women meeting criteria for borderline personality disorder. Drug and Alcohol Dependence, 67, 13-26.

Lischetzke, T., \& Eid, M. (2003). Is attention to feelings beneficial or detrimental to affective well-being? Mood regulation as a moderator variable. Emotion, 3, 361-377.

Little, T. D., Cunningham, W. A., Shahar, G., \& Widaman, K. F. (2002). To parcel or not to parcel: Exploring the question, weighing the merits. Structural Equation Modeling, 9, 151-173.

Lynch, T. R., Morse, J. Q., Mendelson, T., \& Robins, C. J. (2003). Dialectical behavior therapy for depressed older adults: A randomized pilot study. American Journal of Geriatric Psychiatry, 11, 33-45.

Lynch, T. R., Trost, W. T., Salsman, N., \& Linehan, M. M. (2007). Dialectical behavior therapy for borderline personality disorder. Annиal Review of Clinical Psychology, 3, 181-205.

Marchesi, C., Fontò, S., Balista, C., Cimmino, C., \& Maggini, C. (2005). Relationship between alexithymia and panic disorder: A longitudinal study to answer an open question. Psychotherapy and Psychosomatics, $74,56-60$.

Margraf, M., \& Berking, M. (2005). Mit einem "Warum" im Herzen lässt sich fast jedes "Wie" ertragen: Konzeption und empirische Evaluation eines psychotherapeutischen Entschlusstrainings [With a "why" in your heart, every "how" becomes bearable: Development and evaluation of a decision-making training]. Verhaltenstherapie, 12, 254-262.

Mennin, D. S., Heimberg, R. G., Turk, C. L., \& Fresco, D. M. (2002). Applying an emotion regulation framework to integrative approaches to generalized anxiety disorder. Clinical Psychology: Science and Practice, 9, 85-90.

Mennin, D. S., Heimberg, R. G., Turk, C. L., \& Fresco, D. M. (2005). 
Preliminary evidence for an emotion dysregulation model of generalized anxiety disorder. Behaviour Research and Therapy, 43, 1281-1310.

Morrow, J., \& Nolen-Hoeksema, S. (1990). Effects of responses to depression on the remediation of depressive affect. Journal of Personality and Social Psychology, 58, 519-527.

Moses, E. B., \& Barlow, D. H. (2006). A new unified treatment approach for emotional disorders based on emotion science. Current Directions in Psychological Science, 15, 146-150.

Nolen-Hoeksema, S. (2000). The role of rumination in depressive disorders and mixed anxiety/depressive symptoms. Journal of Abnormal Psychology, 109, 504-511.

Nolen-Hoeksema, S., \& Harrell, Z. A. (2002). Rumination, depression, and alcohol use: Tests of gender differences. Journal of Cognitive Psychotherapy, 16, 391-403.

Radloff, L. S. (1977). The CES-D Scale: A self-report depression scale for research in the general population. Applied Psychological Measurement, 3, 385-401.

Radloff, L. S. (1991). The use of the Center for Epidemiologic Studies Depression Scale in adolescents and young adults. Journal of Youth and Adolescence, 20, 149-166.

Rusting, C. L., \& Nolen-Hoeksema, S. (1998). Regulating responses to anger: Effects of rumination and distraction on angry mood. Journal of Personality and Social Psychology, 74, 790-803.

Safer, D. L., Telch, C. F., \& Agras, W. S. (2001). Dialectical behavior therapy for bulimia nervosa. American Journal of Psychiatry, 158, 632-634.

Salovey, P., Mayer, J. D., Goldman, S. L., Turvey, C., \& Palfai, T. P. (1995). Emotional attention, clarity, and repair: Exploring emotional intelligence using the Trait Meta-Mood Scale. In J. W. Pennebaker (Ed.), Emotion, disclosure, and health (pp. 125-154). Washington, DC: American Psychological Association.

Schafer, J. L., \& Graham, J. W. (2002). Missing data: Our view of the state of the art. Psychological Methods, 7, 147-177.

Seiffge-Krenke, I. (2000). Causal links between stressful events, coping style, and adolescent symptomatology. Journal of Adolescence, 23, 675-691.

Silk, J. S., Steinberg, L., \& Morris, A. (2003). Adolescents' emotion regulation in daily life: Links to depressive symptoms and problem behavior. Child Development, 74, 1869-1880.

Sim, L., \& Zeman, J. (2004). Emotion awareness and identification skills in adolescent girls with bulimia nervosa. Journal of Clinical Child and Adolescent Psychology, 33, 760-771.

Southam-Gerow, M. A., \& Kendall, P. C. (2002). Emotion regulation and understanding: Implications for child psychopathology and therapy. Clinical Psychology Review, 22, 189-222.

Spielberger, C. D. (1983). Manual for the State-Trait Anxiety Inventory STAI (Form Y). Palo Alto, CA: Consulting Psychologists Press.

SPSS. (2005). SPSS 14.0 user's guide. Chicago: Author.

Stankov, L. (1999). Mining on the "no man's land" between intelligence and personality. In P. L. Ackerman, P. C. Kyllonen, \& R. D. Roberts (Eds.), Learning and individual differences: Process, trait, and content determinants (pp. 315-337). Washington, DC: American Psychological Association.

Teasdale, J. D., \& Barnard, P. J. (1993). Affect, cognition, and change: Remodeling depressive thought. Hove, United Kingdom: Erlbaum.

Telch, C. F., Agras, W., \& Linehan, M. M. (2001). Dialectical behavior therapy for binge eating disorder. Journal of Consulting and Clinical Psychology, 69, 1061-1065.

Walcott, C. M., \& Landau, S. (2004). The relation between disinhibition and emotion regulation in boys with attention deficit hyperactivity disorder. Journal of Clinical Child \& Adolescent Psychology, 33, 772782.

Watson, D., Clark, L. A., \& Tellegen, A. (1988). Development and validation of brief measures of positive and negative affect: The PANAS scales. Journal of Personality and Social Psychology, 54, 1063-1070.

Williams, F. M., Fernández-Berrocal, P., Extremera, N., Ramos-Díaz, N., \& Joiner, T. E. (2004). Mood regulation skill and the symptoms of endogenous and hopelessness depression in Spanish high school students. Journal of Psychopathology and Behavioral Assessment, 26, 233-240.

Received May 20, 2008

Revision received August 1, 2008

Accepted August 1, 2008 